\title{
Motor neuron disease and polio in Scotland
}

\author{
R J Swingler, H Fraser, C P Warlow
}

\begin{abstract}
An analysis of mortality and morbidity rates for motor neuron disease (MND) in Scotland has confirmed earlier observations that the disease is more common in men and older age groups. The geographical distribution is non-uniform and related to discharge rates for all neurological diseases. Discharge and mortality rates are increasing but there has been no decline in populations who would have been vaccinated against polio.
\end{abstract}

(F Neurol Neurosurg Psychiatry 1992;55:1116-1120)

The general term motor neuron disease (MND) refers to those conditions characterised by progressive muscle wasting and weakness caused by a variable combination of upper and lower motor neuron degeneration. Five to $10 \%$ of cases are familial and in some pedigrees there is evidence of a gene conferring disease susceptibility located on chromosome 21. ${ }^{1}$ Most cases are sporadic, however, and the low concordance rate demonstrated in twin studies provides strong evidence for an exogenous aetiology in this group. ${ }^{2}$ In most patients there is no identifiable cause, and although toxic, metabolic, traumatic, infectious and immunological mechanisms have come under close scrutiny, the aetiology is unknown. ${ }^{34}$

There has been longstanding interest in viral hypotheses and the role of poliovirus has received most attention. Charcot was the first to propose a relationship between poliomyelitis and the later development of progressive muscular atrophy in the discussion of a case reported by Raymond ${ }^{5}$ and the association has since been described in several case series. ${ }^{67}$ Evidence for an association is conflicting, however, ${ }^{810}$ and most patients have no history of this condition. Nevertheless, polio infection is usually asymptomatic ${ }^{11}$ and Mar$\operatorname{tyn}^{1213}$ argued that, even in patients with no history of poliomyelitis, subclinical infection might be severe enough to deplete motor neurons and that MND might then develop as a consequence of further motor neuron loss due to ageing or a second insult. If this hypothesis is correct, the epidemiology of polio and MND should be related and, in this study, a comparison was made of Scottish mortality and morbidity returns for both conditions.

\section{Method}

Morbidity data

Since 1968, information about patients dis- charged from Scottish hospitals has been entered on computers by the Common Services Agency for the purposes of the Scottish Hospitals In Patient Survey. ${ }^{14}$ Entries for patients discharged with a diagnosis of motor neuron disease (International Classification of Diseases, eighth revision (ICD8) code 348 from 1965 to 1978 and ICD9 code 335 from 1979 onwards) were retrieved for the period 1968-87 and the data were indexed by name and date of birth to link the records and identify individuals who were discharged with this syndrome for the first time. Discharge rates for all neurological diseases (ICD 320-389) were obtained from Scottish hospital inpatient statistics ${ }^{14}$ and these included first and subsequent discharges. Data on the uptake of polio vaccines and notification rates for poliomyelitis were obtained from Scottish Office publications for the period 1931-87. ${ }^{15}$

\section{Mortality data}

Mortality statistics for MND, poliomyelitis and other neurological diseases were obtained from publications of the Registrar General for Scotland. ${ }^{1617}$ Mortality returns for progressive muscular atrophy were first made in 1931 (ICD4 code 81.1 from 1931 to 37 ). In 1938 the classification was widened to include motor neuron disease (ICD5 code 82 from 1938 to 1947). Since then the categories have been slightly modified (ICD6 and ICD7 code 356 from 1948 to 1964 , ICD8 code 348 from 1965 to 1978) and in the most recent revision, MND was classified with other anterior horn cell diseases (ICD9 code 335 since 1979). The classification of acute poliomyelitis has remained reasonably constant since 1929: (ICD4 code 16, ICD5 code 36, ICD6 and 7 codes 80 , ICD8 code 40 , ICD9 code 45 ). The same source was also used to obtain mortality returns for all neurological diseases (ICD9 320-389) between 1968 and 1987 .

\section{Demographic data}

Population estimates for Scotland were obtained from the annual reports of the Registrar General for the years $1931-87^{18}$ and additional demographic data were obtained from the county census reports for 1931 and small area statistics from the 1981 census. ${ }^{19} 20$

\section{Age-sex distribution}

Age-sex-specific first discharge and mortality rates for MND were calculated for the period 1968-87, using the 1981 population as the denominator. Poisson tables were used to estimate $95 \%$ confidence intervals. ${ }^{21}$ 


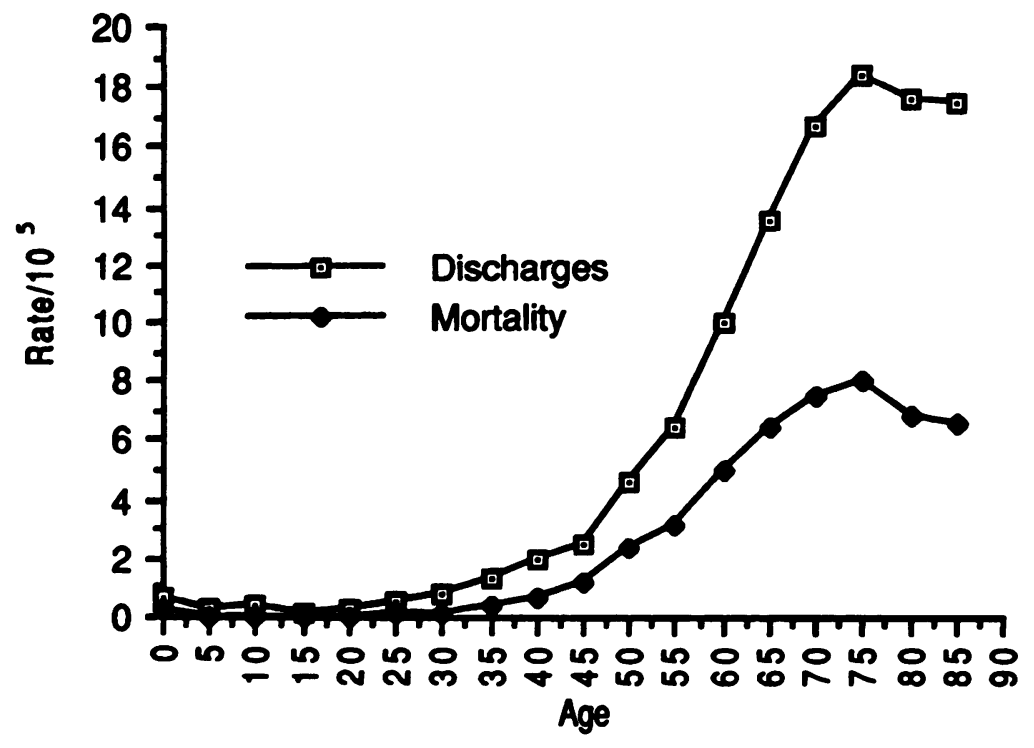

Figure 1 Age-specific discharge and mortality rates for motor neuron disease.

Temporal variations in mortality and morbidity Temporal trends were analysed by determining the mortality rate for poliomyelitis, progressive muscular atrophy and motor neuron disease between 1931 and 1987. The population estimates for the first year of each quinquennium for this period were used as the denominator. Age-specific first discharge and mortality rates were also calculated for the 20-year period from 1968 to 1987 using the annual estimate of the usually resident population as a denominator. The age-sex-specific rates for 1968 to 1987 were then used to calculate annual standardised discharge and mortality ratios for this 20 year period using the method of indirect standardisation (Scotland 1968-87 = 100). ${ }^{22}$ The statistical significance of the observed temporal trends was examined using Poisson regression techniques to calculate the average proportionate change in mortality and morbidity per year, together with $95 \%$ confidence intervals.

\section{Geographical variations in mortality and morbidity}

Crude mortality rates for poliomyelitis and MND (1931-49) were calculated for the 33 counties of Scotland using 1931 estimates of the population as a denominator. These were compared with crude mortality and discharge

Table 1 Notification and mortality rates for acute poliomyelitis in Scotland 1931-88*

\begin{tabular}{lcc}
\hline Year & $\begin{array}{l}\text { Notifications } \\
(\text { rate/10 })\end{array}$ & Deaths (rate/106) \\
\hline $1931-35$ & $272(11 \cdot 09)$ & $74(3.02)$ \\
$1936-40$ & $561(22 \cdot 64)$ & $73(2 \cdot 95)$ \\
$1941-45$ & $444(18 \cdot 85)$ & $72(3.06)$ \\
$1946-50$ & $2921(114 \cdot 29)$ & $245(9 \cdot 59)$ \\
$1951-55$ & $1996(77 \cdot 96)$ & $92(3.59)$ \\
$1956-60$ & $1104(42 \cdot 69)$ & $37(1 \cdot 43)$ \\
$1961-65$ & $191(7 \cdot 35)$ & $4(0 \cdot 15)$ \\
$1966-70$ & $6(0 \cdot 23)$ & $0(0.00)$ \\
$1971-75$ & $8(0.31)$ & $1(0.04)$ \\
$1976-80$ & $2(0.08)$ & $1(0.04)$ \\
$1981-85$ & $3(0 \cdot 12)$ & $0(0.00)$ \\
$1986-88$ & $1(0.07)$ & $0(0.00)$ \\
\hline
\end{tabular}

*Calculated using the population estimate for the first year of each quinquennium as the denominator. rates for MND between 1968 and 1974, adjusted to estimates of the population resident in 1968. In 1974 the administrative boundaries of Scotland were changed and the 33 counties were reorganised into nine regions, three island areas, 53 districts and 1211 postcode sectors. Crude mortality rates for regions, island areas and districts were calculated for the period 1975-87 by using the 1981 estimates of population as a denominator. ${ }^{20}$ Postcodes were used to identify the area of residence of patients discharged between 1975 and 1987 and, using these data, it was possible to calculate crude discharge rates to postcode sector level for the same period. Age-sex standardised discharge and mortality ratios for regions and districts were then calculated by the indirect method (Scotland 1975-87= 100). ${ }^{22}$ Confidence intervals were calculated using tables of the Poisson distribution ${ }^{21}$ and the results were mapped to postcode sector level using Linemap, the computerised mapping programme. ${ }^{23}$

\section{Results}

\section{Age-sex distribution}

Between 1968 and 1987, 6009 patients were discharged from public Scottish hospitals with a diagnosis of MND and the data were linked to identify 3802 individuals who were classified as having this syndrome for the first time. The mean discharge rate was $3 \cdot 69 / 10^{5}$ per year and the disease was more common in men $\left(4 \cdot 33 / 10^{5}\right.$ per year) than women $\left(3 \cdot 09 / 10^{5}\right.$ per year). The mean age of discharged patients was 61.9 years (SD 16.6). There were 2153 $(56.6 \%)$ men and they were slightly younger $(60.7$ years, SD16.3) than the women $(63.4$ years, SD 16.7).

Progressive muscular atrophy or motor neuron disease was recorded as the underlying cause of death in $\mathbf{4 2 7 2}$ registrations between 1931 and 1987, and 1673 of these returns were made between 1968 and 1987. Age-sex-specific discharge and mortality rates are shown in figure 1 . The mean mortality rate was $1 \cdot 62 / 10^{5}$ per year and again the mortality rate was higher in men $\left(1 \cdot 79 / 10^{5}\right.$ per year) than women $\left(1 \cdot 47 / 10^{5}\right.$ per year). The disease was more common in men in all age groups and incidence increased with age. Peak morbidity was observed in 80-84 year olds with mortality becoming maximal in the 65-69 year age group.

\section{Temporal variations}

The Salk vaccine was introduced to Scotland in 1956 and surveys in 1961 indicate that $48 \%$ of the population born between 1933 and 1942 and $85 \%$ of those born between 1943 and 1961 were vaccinated. The live (Sabin) vaccine was introduced in 1962 and infant vaccination rates of $85 \%$ have been recorded since. These measures have been accompanied by a marked decline in polio notifications and mortality (table 1) from a peak of 114 and $9 \cdot 6 / 10^{6}$ per year respectively between 1946 and 1950 to virtually zero in recent years.

Between 1968 and 1987, crude first dis- 
Table 2 Standardised first discharge and mortality ratios for motor neuron disease in Scotland 1968-87*

\begin{tabular}{llc}
\hline Year & $\begin{array}{l}\text { Standardised } \\
\text { discharge ratios }\end{array}$ & $\begin{array}{l}\text { Standardised } \\
\text { mortality ratios }\end{array}$ \\
\hline 1968 & 113 & 78 \\
1969 & 95 & 73 \\
1970 & 83 & 83 \\
1971 & 66 & 67 \\
1972 & 95 & 72 \\
1973 & 88 & 84 \\
1974 & 79 & 87 \\
1975 & 83 & 85 \\
1976 & 79 & 105 \\
1977 & 83 & 105 \\
1978 & 78 & 90 \\
1979 & 76 & 107 \\
1980 & 106 & 96 \\
1981 & 108 & 99 \\
1982 & 84 & 96 \\
1983 & 115 & 98 \\
1984 & 100 & 114 \\
1985 & 122 & 108 \\
1986 & 119 & 125 \\
1987 & 117 & 124 \\
\hline
\end{tabular}

* Using the annual estimate of the usual resident population as

a denominator. Average proportionate change in age-spec

$0-19$ years $=1.058(95 \% \mathrm{Cl} 1.026$ to 1.090$)$

$0-19$ years $=1.058(95 \%$ Cl 1.026 to 1.090$)$

$20-39$ years $=0.983(95 \%$ CI 0.521 to 1.009$)$

$40-59$ years $=1.007(95 \%$ CI 0.100 to 1.019$)$

$60-79$ years $=1.017(95 \%$ CI 1.010 to 1.025$)$

$80-99$ years $=1.055(95 \%$ CI 1.034 to 1.076$)$

Average proportionate change in age-specific mortality per year with $95 \%$ confidence intervals.

$0-19$ years $=1 \cdot 168(95 \%$ CI 1.090 to $1 \cdot 254)$

$20-39$ years $=1.012(95 \%$ CI 0.960 to 1.067$)$

$40-59$ years $=1.017(95 \%$ CI 1.001 to 1.034$)$

$60-79$ years $=1.028(95 \%$ CI 1.011 to 1.039$)$

$80-99$ years $=1.035(95 \%$ CI 1.002 to 1.068$)$

charge rates for $\mathrm{MND}$ increased significantly from 4.13 to $4.52 / 10^{5}$ per year $(\mathrm{p}<0.05)$ (figure 2) and an analysis of age-specific discharge rates demonstrated significant $(\mathrm{p}<0.05)$ increases in the $0-19,60-79$ and 80-99 year age groups (table 2). Age-sex standardised discharge ratios also increased significantly from 113 to $117(\mathrm{p}<0.05)$ but hospital discharges for all neurological diseases almost doubled over this period and the proportion of patients discharged with MND declined slightly from $2 \cdot 4$ to $1 \cdot 5 \%$.

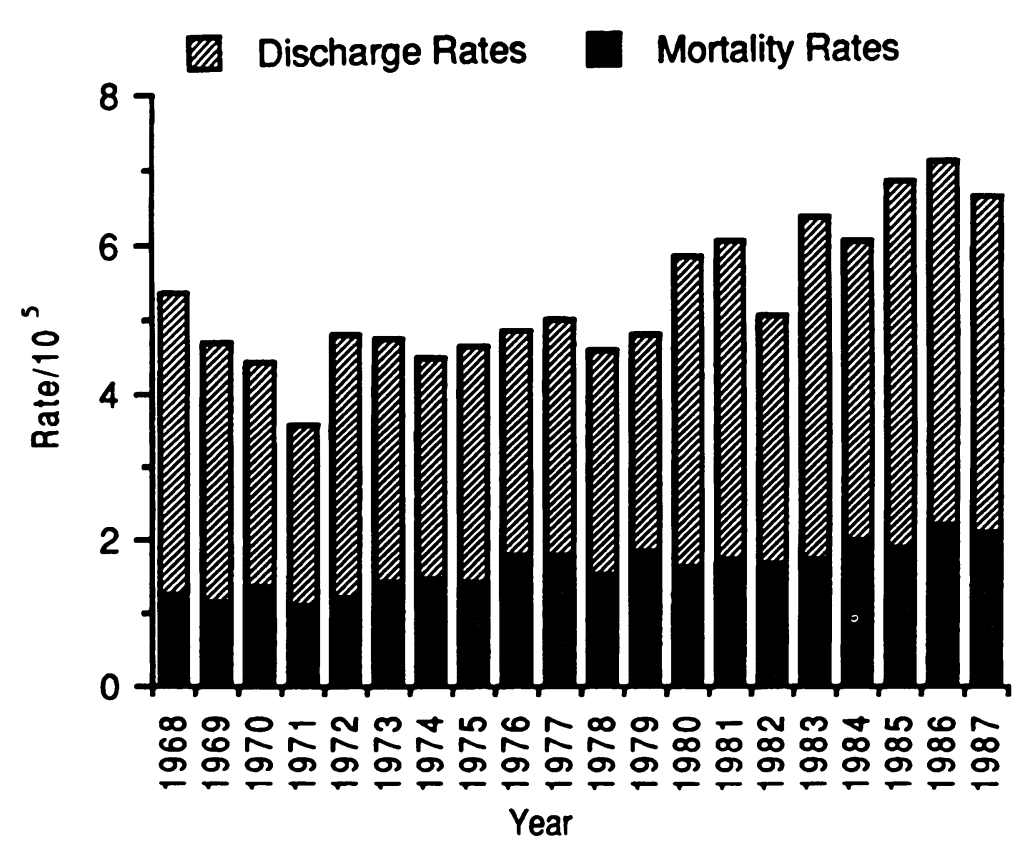

Figure 2 Discharge and mortality rates for motor neuron disease 1968-87.
Over the same 20 year period, crude mortality rates for MND also increased significantly from $1 \cdot 25$ to $2 \cdot 1 / 10^{5}$ per year $(p<0.05)$ and age-specific mortality rates rose significantly $(\mathrm{p}<0.05)$ in the $0-19$ and $40+$ year age groups (table 2). Age-sex standardised mortality ratios increased significantly from 78 to 124 $(\mathrm{p}<0.05)$ and, whilst the number of patients dying from all neurological diseases increased, the proportion with MND still rose significantly from 9.5 to $13 \%(\mathrm{p}<0.05)$.

\section{Geographical variations}

Mortality from progressive muscular atrophy (1931-49) was significantly higher in rural areas $(r=0.51 ; 95 \%$ confidence interval 0.20 to 0.73 ) and there were negative associations between mortality rates for polio for this early period and more recent first discharge and mortality rates for $M N D$ for the period 1968-74 $(r=-0 \cdot 48 ; 95 \%$ confidence interval -0.71 to -0.16 and $r=-0.21 ; 95 \%$ confidence interval -0.52 to 0.15 respectively).

The postcodes of area of residence were available for $2403(92 \%)$ of the MND patients hospitalised for the first time between 1975 and 1987 (table 3, figure 3). Significant variations were observed with standard discharge ratios ranging from 34 in the Fife region to 119 in the Borders region. Standardised mortality ratios were also non-uniform with values ranging between 77 in the Fife region to 156 in the island areas. Standardised first discharge ratios for MND were inversely related to population density $(r=-0.31 ; 95 \%$ confidence interval -0.53 to -0.05$)$ and strongly associated with discharge rates for all neurological conditions $(r=0.78 ; 95 \%$ confidence interval 0.38 to $0.94)$.

\section{Discussion}

Variations in the incidence of MND should provide clues to underlying aetiology, but it is difficult to measure this statistic because the condition is rare and the onset is insidious. In the United Kingdom morbidity and mortality returns are collected routinely by government agencies and these should provide some information about the frequency of this disease. Holloway has observed that first discharge data tend to overestimate incidence by as much as $100 \%$ because of false-positive coding and diagnosis, ${ }^{2425}$ and mortality returns tend to under represent incidence because of noncertification in $20-30 \%$ of cases. ${ }^{26} 29$ Despite these problems morbidity and mortality provide upper and lower limits of incidence so it was possible to use these statistics to test the hypothesis that the distribution of poliomyelitis and MND are related.

\section{Age-sex distribution}

MND morbidity and mortality increased with age and were more common in adult males. The slight decline in the older age groups is probably related to underascertainment. Between 1975 and 1987, 295 (11\%) of the first discharge registrations and $88(7 \cdot 3 \%)$ of mortality returns related to individuals younger 
Table 3 Crude hospital first discharge and mortality rates for MND and standardised first discharge and mortality ratios for the 9 regions and island areas of Scotland (1975-87)

\begin{tabular}{|c|c|c|c|c|c|c|c|}
\hline Region & Population & $\begin{array}{c}\text { First } \\
n\end{array}$ & $\begin{array}{l}\text { tischarges } \\
\text { Rate }\left(110^{5}\right)\end{array}$ & $\begin{array}{l}\text { Standardised first } \\
\text { discharge ratios } \\
(95 \% \text { CI })\end{array}$ & $\begin{array}{c}\text { Deaths } \\
n\end{array}$ & $s^{s}$ Rate $\left(/ 10^{5}\right)$ & $\begin{array}{l}\text { Standardised mortality } \\
\text { ratios } \\
(95 \% C I)\end{array}$ \\
\hline $\begin{array}{l}\text { Borders } \\
\text { Central } \\
\text { Dumfries } \\
\text { Fife } \\
\text { Grampion } \\
\text { Highland } \\
\text { Lothian } \\
\text { Strathclyde } \\
\text { Tayside } \\
\text { Island areas } \\
\text { Area not known } \\
\text { Scotland }\end{array}$ & $\begin{array}{r}97218 \\
268115 \\
141890 \\
325066 \\
462891 \\
187004 \\
723108 \\
2375410 \\
382707 \\
71906 \\
\mathrm{ND} \\
5035315\end{array}$ & $\begin{array}{r}71 \\
121 \\
71 \\
58 \\
203 \\
106 \\
412 \\
1109 \\
205 \\
48 \\
194 \\
2598\end{array}$ & $\begin{array}{l}5 \cdot 62 \\
3 \cdot 47 \\
3 \cdot 85 \\
1 \cdot 37 \\
3 \cdot 37 \\
4 \cdot 36 \\
4 \cdot 38 \\
3 \cdot 59 \\
4 \cdot 12 \\
5 \cdot 13 \\
\mathrm{ND} \\
3 \cdot 97\end{array}$ & $\begin{array}{r}119(93-151) \\
91(176-109) \\
89(169-114) \\
34(26-44)^{\star \star} \\
85(73-97)^{\star \star} \\
110(90-133) \\
109(99-120) \\
93(88-99)^{\star \star} \\
95(83-109) \\
117(86-155) \\
\text { ND ND } \\
100(96-104)\end{array}$ & $\begin{array}{c}37 \\
76 \\
33 \\
61 \\
93 \\
55 \\
217 \\
498 \\
110 \\
29 \\
\mathrm{ND} \\
1209\end{array}$ & $\begin{array}{l}2 \cdot 93 \\
2 \cdot 18 \\
1 \cdot 79 \\
1 \cdot 44 \\
1 \cdot 55 \\
2 \cdot 26 \\
2 \cdot 31 \\
1 \cdot 61 \\
2 \cdot 21 \\
3 \cdot 10 \\
\text { ND } \\
1 \cdot 85\end{array}$ & $\begin{array}{l}134(94-185) \\
123(97-154) \\
89(61-125) \\
77(59-99)^{\star \star} \\
84(68-103) \\
124(93-161) \\
124(108-142)^{\star \star} \\
90(82-98)^{\star \star} \\
110(90-132) \\
156(105-224) \\
\text { ND ND } \\
100(94-106)\end{array}$ \\
\hline
\end{tabular}

Using the 1981 population as the denominator.

$\star \star$ Significantly higher or lower than expected.

ND $=$ No data

than 45 years. Whilst it was not possible to determine the vaccination status of these patients, Scottish office statistics indicate that $85 \%$ of the population born since 1943 have been vaccinated against polio.

\section{Temporal trends}

In an earlier study from Scotland, Holloway suggested morbidity and mortality from MND were increasing. ${ }^{24}$ Our study confirms her earlier findings and similar trends have been observed in England and Wales, ${ }^{126}$ the United States ${ }^{30}$ and Norway. ${ }^{31}$ Swash has argued that these temporal trends may be explained by the rising number of medical practitioners able to make the diagnosis. ${ }^{32}$ But, whilst it is true that the number of neurologists has increased, especially in the United States, there has been no comparable increase in the frequency of Parkinson's disease ${ }^{33}$ in that

Figure 3 Mean discharge rates for motor neuron disease in the Health Boards of Scotland 1975-87. country and the improvements in neurological services in the United Kingdom and Scandinavia have been more modest. Moreover, as the proportion of neurological patients dying from MND has increased significantly it would seem likely that the observed trends reflect a real increase in underlying disease frequency with some additional inflation due to superior case ascertainment and changes in disease classification.

These observations would obviously lend support to the hypothesis that MND is caused by an exogenous factor and, if the polio hypothesis is correct, it is possible to predict a rise in disease frequency, reflecting changes in the incidence of poliomyelitis that occurred in the earlier part of the century, followed by a decline after 2010 as the effects of vaccination become apparent. ${ }^{1213}$ Epidemiological studies of serological status indicate, however, that antibodies may be acquired in the second decade of life e $^{345}$ and, if such at-risk populations were successfully vaccinated in the 1960 s, one would expect to see an effect on morbidity and mortality as these patients enter the third and fourth decades in the 1980s. But, although polio mortality and notification rates have declined to vanishingly low levels, these changes have not been accompanied by any significant reduction in MND mortality or morbidity in populations who would have been vaccinated.

\section{Geographical variations}

In this study there was no evidence of a geographical association between past mortality from poliomyelitis and present morbidity or mortality from MND. It was not possible to replicate Martyn's study exactly because polio notification rates were not available on a regional basis. In an earlier study from Scotland, Holloway observed that the disease was more common in rural areas ${ }^{25}$ but, while this was also true of the present study, standardised first discharge ratios were more strongly correlated with discharge rates for all neurological diseases, indicating that the observed trends might be related to variations in ascertainment.

To conclude, we have found no evidence that MND is caused by early asymptomatic polio infection or that polio vaccination offers protection against this condition. However, 
these results must be interpreted with caution because the population is small and both geographical and temporal trends can be biased by variations in case ascertainment and data collection. It will therefore be of critical importance to monitor the incidence of MND in vaccinated populations and perform casecontrol studies to examine social conditions and vaccination status in early life. We thank the Information and Statistics Division of the
Common Services Agency of the Scottish Health Service, the Gemeral Register Office of Scotland, the National Library of General Register Office of Scotland, the National Library of Scotland and Edinburgh University Data Library for supplying data and Mr Nimmo of the Northern Health Boards Operational Research Unit, Department of Community Medicine, Aberdeen for providing the LineMap programme. We would
also like to thank Dr S Holloway, Department of Medical Genetics, University of Edinburgh, for access to earlier data collected in Scotland. Dr Andrew Chancellor and Mr S Ogston made helpful comments about the study. This work was supported by a grant from the Scottish Motor Neurone Disease Association.

1 Siddique T, Figlewicz D, Pericak-Vance MA, et al. Linkage of a gene causing familial amyotrophic lateral sclerosis to chromosome 21 and evidence of genetic-locus heterogeneity. New Engl f Med 1991;324:1381-4.

2 Hawkes CH, Graham AJ. What causes MND? (letter) Lancet 1991;337:180.

3 Mitsumoto H, Hanson MR, Chad DA. Amyotrophic latera sclerosis-recent advances in pathogenesis and therapeutic trials. Arch Neurol 1988;45:189-202.

4 Anon. What causes motoneuron disease? Lancet 1990 336: $1033-5$.

5 Raymond $M$ (with contribution by Charcot JM): Paralysie essentiele de l'enfance: atrophie musculaire consecutive, 4th series, vol 4. Gaz Med Paris 1875:225-6.

6 Potts CS. A case of progressive muscular atrophy occurring in a man who had had acute poliomyeltis nineteen years in a man who had had acute poliomyeltis nineteen years previously, with a review of the literature bearing upon the relations of infantile paralysis to the spin

7 Salman LA, Riley HA. The relation between chronic anterior poliomyelitis or progressive spinal muscula atrophy and an antecedent attack of acute anterio poliomyelitis. Bull Neurol Inst NY 1935;4:35-63.

8 Zilkha KJ. Untitled discussion. Proc $R$ Soc Med 1962;55: 1028-9.

9 Poskanzer DC, Cantor HM, Kaplan GS. The frequency of preceding poliomyelitis in amyotrophic lateral sclerosis. In: Norris FH, Kurland I T, eds. Motor Neuron Disease. New York: Grune and Stratton, 1969:286-90.

10 Deapen DM, Henderson BE. A case-control study of amyotrophic lateral sclerosis. Am $\mathcal{f}$ Epidemiol 1986 123:790-9.
11 Department of Health and Social Security, Welsh Office, Scottish Home and Health Department. Immunisation against infectious disease. London: HMSO, 1988.

12 Martyn CN, Barker DJP, Osmond C. Motoneurone disease and past poliomyelitis in England and Wales. Lancet 1988; : 1319-22.

13 Martyn CN. Poliovirus and motor neurone disease. $\mathcal{F}$ Neurol 990;237:336-8.

14 Common Services Agency of the Scottish Health Service. Scottish hospital in-patient statistics, 1968-1987. Edinburgh: Common Services Agency, 1969-88.

15 Scottish Home and Health Department. Annual reports, 1931-1987. Edinburgh: HMSO, 1932-88.

16 Alderson M. International mortality statistics. London: Macmillan, 1981.

17 Registrar General, Scotland. Annual Reports, 1931-1987. Edinburgh HMSO, 1932-88.

18 Registrar General, Scotland Annual estimates of population 1968-87. Edinburgh: HMSO, 1969-88.

19 Registrar General Scotland Census of Scotland, 1931 Edinburgh: HMSO, 1932.

20 Registrar General, Scotland. Census of Scotland, 1981. Edinburgh: HMSO, 1932.

21 Lentner C. Geigy scientific tables. Basle: Ciba Geigy 1982: 223-4.

22 Alderson M. An introduction to epidemiology. London: Macmillan, 1983.

23 Nimmo AW. The Chief Scientist reports... Review of computer mapping of health data. Health Bull 1989 47:40-53.

24 Holloway SM, Mitchell JD. Motor neurone disease in the Lothian Region of Scotland 1961-1981. I Epidemiolog Commun Health 1986;40:344-50.

25 Holloway SM, Emery AEH. The epidemiology of motor neuron disease in Scotland. Musc Nerve 1982:5:131-3.

26 Buckley J, Warlow C, Smith P, Hamilton-Jones D, Irvine S Buckley J, Warlow C, Smith P, Hamilton-Jones D, Irvine S, 1959-1979. I Neurol Neurosurg Psychiatry 1983;46: 197-205.

27 O'Malley, Dean G, Elian M. Multiple sclerosis and motor neurone disease: survival and how certified after death. $\mathcal{F}$ Epidemiol Commun Health 1987;41:14-7.

28 Qizilbash N, Bates D. Incidence of motor neurone disease in the northern region. 7 Epidemiol Commun Health 1987;41:18-20.

29 Bharucha NE, Schoenberg BS, Raven RH, Pickle LW, Byar DP, Manson TJ. Geographical distribution of motor neurone disease and correlation with possible etiological neurone disease and correlation with

30 Lilienfeld DE, Chan E, Ehland J, et al. Rising mortality from motoneuron disease in the USA, 1962-1984. Lancet from motoneuri:

31 Flaten TP. Rising mortality from motoneuron disease. Lancet 1989; i:1018-9.

32 Swash M, Schwartz MS, Li T-M. Trends in mortality from motoneuron disease. Lancet 1989;i:958.

33 Lilienfeld DE, Chan E, Ehland J, et al. Two decades of increasing mortality from Parkinson's disease in the elderly. Arch Neurol 1990;47:731-4.

34 Backett EM. Social patterns of antibody to poliovirus. Lancet 1957; i:778.

35 Macleod RC, MacGregor LG, Larminie HE, Grist NR. Serological epidemiology of poliomyelitis in central Scotland. Scot Med $\mathcal{F} 1958 ; 3: 76-81$. 